\title{
How does the use of polytetrafluoroethylene neochordae for posterior mitral valve prolapse (loop technique) compare with leaflet resection? A prospective randomized trial
}

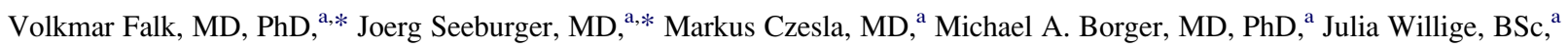
Thomas Kuntze, MD, ${ }^{a}$ Nicolas Doll, MD, PhD, ${ }^{a}$ Franka Borger, MD, ${ }^{a}$ Patrick Perrier, MD,${ }^{b}$ and Friedrich W. Mohr, MD, PhD ${ }^{\mathrm{a}}$

\begin{abstract}
Objective: Mitral valve surgery for posterior mitral leaflet prolapse consists mostly of leaflet resection, but implantation of premeasured polytetrafluoroethylene neochordae (ie, loops) is another option. The aim of this prospectively randomized trial was to determine how preservation of leaflet structure in combination with premeasured neochordae compares with the widely adopted technique of leaflet resection.
\end{abstract}

Methods: A total of 129 patients with severe mitral regurgitation, with a mean mitral regurgitation grade of $3.6 \pm$ 0.6 , underwent minimal invasive mitral valve surgery through a right lateral mini-thoracotomy. The mean age was $59.5 \pm 12$ years, 90 patients were male, the mean preoperative ejection fraction was $65 \% \pm 8 \%$, and the mean New York Heart Association functional class was $2.1 \pm 0.7$. Posterior mitral leaflet prolapse was diagnosed in all patients. Randomization was performed preoperatively, and crossover was allowed if the surgeon deemed it medically necessary. Crossover from resection to loops occurred in 9 patients, and crossover from loops to resection occurred in 3 patients.

Results: Mitral valve repair was accomplished in all patients $(n=129,100 \%)$, and all patients received an annuloplasty ring. The mean number of loops implanted on the posterior mitral leaflet was $3.2 \pm 0.9$, with a mean length of $13.3 \pm 2.2 \mathrm{~mm}$. The mean duration of cardiopulmonary bypass was $135 \pm 37$ minutes and the mean aortic crossclamp time was $82 \pm 26$ minutes in all patients, with no significant difference between groups. Intraoperative transesophageal echocardiography showed a significantly longer line of mitral valve leaflet coaptation after implantation of loops $(7.6 \pm 3.6 \mathrm{~mm})$ than after resection $(5.9 \pm 2.6 \mathrm{~mm} ; P=.03)$. Thirty-day mortality was $1.6 \%$ for the entire group (2/129), with both deaths occurring in the loop group. Cause of death was massive pulmonary embolism in 1 patient and acute right heart failure in 1 patient. Early and mid-term echocardiographic follow-up revealed excellent valve function in the majority of patients, with no significant difference in mitral orifice area $\left(3.6 \pm 1.0 \mathrm{~cm}^{2}\right.$ vs $\left.3.7 \pm 1.1 \mathrm{~cm}^{2}, P=.4\right)$.

Conclusion: Both repair techniques for posterior mitral leaflet prolapse are associated with excellent results and appear comparable in the early postoperative course. The loop technique, however, results in a significantly longer line of leaflet coaptation and may therefore be more durable. Longer follow-up is required.

Earn CME credits at

http://cme.ctsnetjournals.org

Several well-described techniques are available for mitral valve (MV) repair. ${ }^{1-3}$ For patients with prolapse of the middle portion of the posterior leaflet (P2), quadrangular resection of the prolapsing segment, as introduced by Carpentier ${ }^{1}$ in 1983, is the most common type of repair. This technique is usually performed in association with plication of the mitral

\footnotetext{
From the Heart Center Leipzig, ${ }^{\text {a }}$ Leipzig, Germany, and Cardiovascular Center Bad Neustadt, ${ }^{\mathrm{b}}$ Bad Neustadt, Germany.

* Volkmar Falk and Joerg Seeburger contributed equally to this article.

Received for publication May 10, 2008; revisions received July 9, 2008; accepted for publication July 14, 2008.

Address for reprints: Joerg Seeburger, MD, Heart Center Leipzig, Leipzig University,

Struempelstrasse 39, 04289 Leipzig, Germany (E-mail: j.seeburger@web.de).

J Thorac Cardiovasc Surg 2008;136:1200-6

$0022-5223 / \$ 34.00$

Copyright $@ 2008$ by The American Association for Thoracic Surgery

doi:10.1016/j.jtcvs.2008.07.028
}

annulus or with a sliding annuloplasty. Although effective, these techniques result in immobilization of the posterior leaflet and impair, to some extent, its physiologic role. ${ }^{4}$ New methods of preserving the posterior leaflet by use of polytetrafluoroethylene (PTFE) neochordae have recently been proposed. ${ }^{3,5,6}$ Although the early and mid-term results for this new procedure are promising, ${ }^{6}$ only retrospective studies have been performed to date. We therefore performed a prospective, randomized clinical trial comparing the use of PTFE neochordae with preservation of the posterior MV leaflet (loop technique) with leaflet resection in patients with prolapse of the posterior leaflet.

\section{MATERIALS AND METHODS \\ Patients}

Patients with isolated prolapse of the posterior leaflet (based on preoperative transthoracic echocardiography findings) undergoing MV repair at the Heart Center Leipzig, Leipzig, Germany, and Cardiovascular Center Bad Neustadt, Bad Neustadt, Germany institution between May of 2005 and October of 2007 were eligible for the study. Of 896 patients who underwent minimally invasive MV surgery during the study period, 326 had no 


\section{Abbreviations and Acronyms \\ $\mathrm{MR}=$ mitral regurgitation \\ $\mathrm{MV}=$ mitral valve \\ PTFE $=$ polytetrafluoroethylene}

prolapse and 273 had anterior or bileaflet prolapse and therefore were ineligible. A total of 297 patients had isolated posterior mitral leaflet prolapse during the study period, of whom $129(43.4 \%)$ were included in the study.

A total of 129 patients with severe mitral regurgitation (MR), with a mean MR grade of $3.4 \pm 0.6$, underwent minimally invasive MV surgery through a right lateral mini-thoracotomy. The mean patient age was $59.5 \pm$ 12 years, and 90 patients $(69.8 \%)$ were male. The mean preoperative left ventricular ejection fraction was $65 \% \pm 8 \%$ for the entire group, and the mean New York Heart Association functional class was 2.1 \pm 0.7 . All patients were diagnosed with posterior mitral leaflet prolapse. MV pathology was myxomatous in all patients. The patient characteristics are shown in Table 1.

\section{Randomization and Ethics Approval}

Treatment assignment was randomized on a 1:1 basis using a computerized random number generator. Randomization was performed immediately before surgery via a sealed envelope, and crossover was allowed if the surgeon deemed it medically necessary. The study was approved by our University Ethics Committee, and patients gave written, informed consent.

\section{Surgical Approach}

A minimally invasive approach was applied in all patients as previously described. ${ }^{7,8}$ In brief, cardiopulmonary bypass was instituted via femoral arterial and venous cannulation through a 3 - to $4-\mathrm{cm}$ transverse incision in the right groin. The tip of the venous cannula was positioned under transesophageal echocardiographic guidance at the junction of the inferior cava and the right atrium. Mild hypothermia $\left(34^{\circ} \mathrm{C}\right)$ was used, and vacuum-assisted venous drainage was applied. A right lateral mini-thoracotomy of 5 to $6 \mathrm{~cm}$ in length was performed in the fourth intercostal space. A port-access video camera was inserted, and a transthoracic aortic crossclamp was used. ${ }^{9}$ Antegrade crystalloid Bretschneider cardioplegia (2 liters) was administered directly into the aortic root and repeated when arrest times exceeded 90 minutes. The surgical field was flooded with carbon dioxide throughout the procedure. MV repair techniques are discussed below. De-airing was performed by filling the left atrium with saline during closure and via the

TABLE 1. Patient characteristics at baseline

\begin{tabular}{lcc}
\hline & Loops & Resection \\
\hline No. of patients & $\mathrm{n}=64$ & $\mathrm{n}=65$ \\
Age, y & $60.4 \pm 11.4$ & $58 \pm 12.7$ \\
NYHA class & $2.0 \pm 0.8$ & $2.2 \pm 0.7$ \\
Hypertension & $36(56.3 \%)$ & $29(44.6 \%)$ \\
Diabetes & $1(1.6 \%)$ & $4(6.2 \%)$ \\
Hypercholesterolemia & $23(35.9 \%)$ & $11(16.9 \%)$ \\
Smoking & $13(20.3 \%)$ & $13(20 \%)$ \\
Stroke & $2(3.13 \%)$ & $4(6.2 \%)$ \\
Pulmonary hypertension & $11(17.2 \%)$ & $13(20 \%)$ \\
Inoperable CAD & $3(4.7 \%)$ & $6(9.2 \%)$ \\
Atrial fibrillation & $20(31.3 \%)$ & $15(23.1 \%)$ \\
Obesity & $12(18.8 \%)$ & $10(15.4 \%)$ \\
\hline NYHA New York Heart Asociation function
\end{tabular}

NYHA, New York Heart Association functional class; $C A D$, coronary artery disease. Continuous variables are expressed as mean \pm standard deviation.
TABLE 2. Intraoperative data

\begin{tabular}{lcc}
\hline \multicolumn{1}{c}{ Operative data } & Loops $(\mathbf{n}=\mathbf{6 9})$ & Resection $(\mathbf{n}=\mathbf{5 3})$ \\
\hline CPB duration & $137 \pm 42$ & $129 \pm 32$ \\
Crossclamp time & $84.1 \pm 25.1$ & $78.6 \pm 27.7$ \\
Surgical techniques & & \\
$\quad$ Complete ring annuloplasty & $54(78 \%)$ & $40(76 \%)$ \\
Partial ring annuloplasty & $15(22 \%)$ & $13(24 \%)$ \\
$\quad$ Mean ring size & $33.1 \pm 2.7$ & $32.8 \pm 1.8$ \\
Concomitant procedure & & \\
Cryoablation & $17(24.6 \%)$ & $12(22.6 \%)$ \\
PFO closure & $6(8.7 \%)$ & $1(1.8 \%)$ \\
TV repair & $1(1.4 \%)$ & $1(1.8 \%)$ \\
Atrial reduction plasty & 0 & $3(5.6 \%)$ \\
\hline
\end{tabular}

$C P B$, Cardiopulmonary bypass; $P F O$, patent foramen ovale; $T V$, tricuspid valve Continuous variables are expressed as mean \pm standard deviation.

cardioplegia puncture site on the ascending aorta. Intraoperative data are depicted in Table 2.

\section{Mitral Valve Repair Techniques}

Details regarding the performance of the resection and loop repair techniques have been described extensively. ${ }^{1,3-5,10,11}$ In patients randomized to receive MV leaflet resection, a standard quadrangular resection of the redundant posterior leaflet tissue was used, followed by approximation of the leaflet remnants using interrupted sutures. The MV repair was completed by a sliding annuloplasty or annular plication whenever necessary. Patients who were randomized to the loop technique underwent our standard approach: The correct length of the PTFE loops (Gore-Tex, WL Gore \& Associates, Flagstaff, Ariz) was assessed using a custom-made caliper, the premade loops were then anchored to the body of the corresponding papillary muscle, and the free loops were attached to the free margin of the prolapsing segment of the posterior leaflet. All patients received an annuloplasty ring, which was a complete, rigid ring (Carpentier-Edwards Physio, Edwards Lifesciences, Irvine, Calif) in the majority of cases. The ring was sized according to the size of anterior MV leaflet and the intertrigonal distance.

\section{Follow-up}

Follow-up was performed at 6 months and at 1 year postoperatively by transthoracic echocardiography and clinical examination. Echocardiographic follow-up was $100 \%$ complete at discharge from hospital, $59 \%$ (76) complete at 6 months, and 31\% (50) complete at 1 year.

\section{Statistical Analyses}

Categoric variables are expressed as proportions, and continuous variables are expressed as mean \pm standard deviations throughout the article. Comparison within and between groups was performed using paired and unpaired Student $t$ tests, respectively. Sample size calculations were based on the ability to detect a significant difference between groups in the postoperative MV orifice area of $0.5 \mathrm{~cm}^{2}$ or more and a difference in leaflet coaptation length of $1.5 \mathrm{~mm}$ or more. These expected values were based on a retrospective analysis of our database. Data were analyzed on an intention-to-treat basis. All analyses were performed using SAS JMP7.0 (SAS Institute, Cary, NC). The standard guidelines for reporting morbidity and mortality after cardiac valvular operations were applied. ${ }^{12}$

\section{RESULTS}

Baseline patient demographics are displayed in Table 1. There were no significant differences between the 2 groups 
of patients for any of the listed variables, with the exception of a higher prevalence of hypercholesterolemia in the patients undergoing loop implantation.

\section{Intraoperative Course}

Successful MV repair was accomplished in all patients. Crossover from resection to loops occurred in 9 patients, and crossover from loops to resection occurred in 3 patients (Figure 1). Seven patients received both treatment modalities and were considered as dropouts. Overall, 69 patients received treatment with the loop technique, and 53 patients received treatment with the leaflet resection technique (Figure 1). Table 2 displays the intraoperative data for both groups of patients. There were no significant differences between groups for any of the variables listed.

Leaflet resection was performed in all 53 patients of the resection group. Of the 69 patients who underwent the loop technique, the mean number of loops implanted on the P2 segment was $3.2 \pm 0.9$. The mean length of loops was $13.3 \pm 2.2 \mathrm{~mm}$.

MR grading at baseline was $4+$ in 35 patients $(26 \%), 3+$ in 77 patients $(61 \%)$, and $2+$ in 17 patients $(13 \%)$. After surgery, 112 patients $(86.8 \%)$ had 0 (none or trace) and 17 patients $(13.2 \%)$ had $1+$ (mild) MR. The mean MR grade decreased from $3.4 \pm 0.6$ at baseline to $0.2 \pm 0.5$ before discharge in the loop group and from $3.4 \pm 0.5$ to $0.1 \pm 0.3$ in the resection group (both $P<.001$ ). Systolic anterior motion of the anterior leaflet was not observed in any patient after either repair technique. Intraoperative transesophageal echocardiography showed a significantly longer line of leaflet coaptation after implantation of loops $(7.6 \pm 3.6 \mathrm{~mm})$ than after leaflet resection $(5.9 \pm 2.6 \mathrm{~mm} ; P=.03)$.

Left ventricular ejection fraction, left atrial size, left ventricular volume, MV orifice area, and transvalvular gradients and velocities showed significant alteration from baseline to after surgery for both groups of patients (Table 3 ). However,

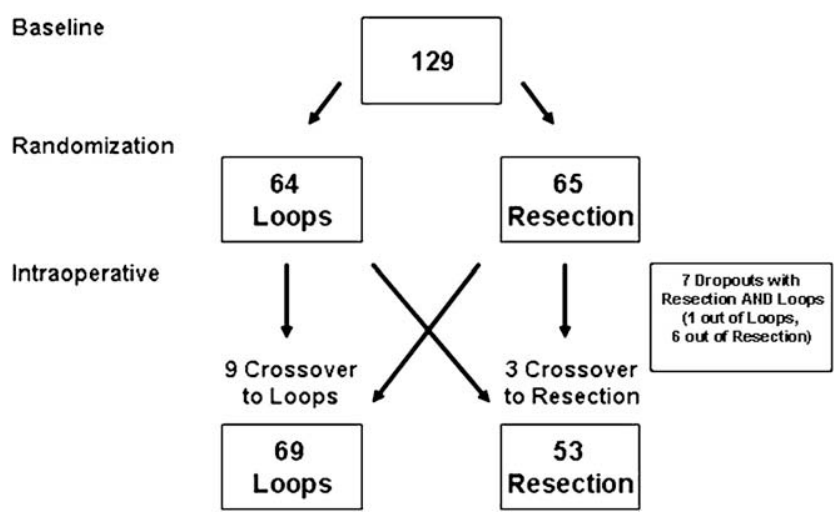

FIGURE 1. Baseline, randomization, and intraoperative management. A total of 129 patients were randomized for MV repair using the loop technique or leaflet resection technique. After crossover and dropouts, 69 patients received loops and 53 patients received resection.
TABLE 3. Echocardiographic outcomes before and after surgery

\begin{tabular}{lccc}
\hline \multicolumn{1}{c}{ MR } & Baseline & After surgery & $\boldsymbol{P}$ value \\
\hline Loops & $3.4 \pm 0.6$ & $0.2 \pm 0.5$ & $P<.001$ \\
Resection & $3.3 \pm 0.5$ & $0.1 \pm 0.3$ & $P<.00$ \\
$P$ value & .74 & .41 &
\end{tabular}

\begin{tabular}{lccc} 
LVEF (\%) & Baseline & After surgery & $\boldsymbol{P}$ value \\
\hline Loops & $65.2 \pm 7.4$ & $60.3 \pm 8.6$ & $P<.001$ \\
Resection & $64.8 \pm 8.3$ & $56.9 \pm 9.0$ & $P<.001$ \\
$P$ value & 14 & .06 &
\end{tabular}

$\begin{array}{lll}P \text { value } & .14 & .06\end{array}$

\begin{tabular}{lccl}
$\boldsymbol{P}$ mean $(\mathbf{m m ~ H g})$ & Baseline & After surgery & $\boldsymbol{P}$ value \\
\hline Loops & $1.98 \pm 0.92$ & $2.54 \pm 1.11$ & $P<.01$ \\
Resection & $1.82 \pm 0.83$ & $3.03 \pm 1.57$ & $P<.001$ \\
$P$ value & 38 & 10 &
\end{tabular}

$P$ value

.38

.10

\begin{tabular}{lccc} 
LA width $(\mathbf{m m})$ & Baseline & After surgery & $\boldsymbol{P}$ value \\
\hline Loops & $51.2 \pm 8.6$ & $44.2 \pm 8.3$ & $P<.001$ \\
Resection & $52.8 \pm 9.1$ & $44.0 \pm 5.5$ & $P<.0001$
\end{tabular}

$P$ value

.91

.36

\begin{tabular}{lccl} 
V mean $(\mathbf{m} / \mathbf{s})$ & Baseline & After surgery & $\boldsymbol{P}$ value \\
\hline Loops & $0.66 \pm 0.15$ & $0.75 \pm 0.15$ & $P<.01$ \\
Resection & $0.64 \pm 0.13$ & $0.8 \pm 0.21$ & $P<.001$ \\
$P$ value & .40 & .12 &
\end{tabular}

\begin{tabular}{lccl}
$\mathbf{L V V d}\left(\mathbf{c m}^{\mathbf{2}}\right)$ & Baseline & After surgery & $\boldsymbol{P}$ value \\
\hline Loops & $125 \pm 39$ & $104 \pm 41$ & $P<.01$ \\
Resection & $135 \pm 41$ & $100 \pm 37$ & $P<.001$ \\
$P$ value & .16 & .53 &
\end{tabular}

\begin{tabular}{lccl} 
MOA $\left(\mathbf{c m}^{\mathbf{2}}\right)$ & Baseline & After surgery & $\boldsymbol{P}$ value \\
\hline Loops & $4.08 \pm 1.21$ & $3.54 \pm 0.96$ & $P<.01$ \\
Resection & $4.23 \pm 1.92$ & $3.72 \pm 1.1$ & $P<.001$ \\
$P$ value & .38 & .34 &
\end{tabular}

Line of coaptation (mm) $\quad$ Loops $\quad$ Resection

\begin{tabular}{llll}
\hline After surgery & $7.6 \pm 3.6 \mathrm{~mm}$ & $5.9 \pm 2.6 \mathrm{~mm}$ & $P=.03$
\end{tabular}

$L V E F$, Left ventricular ejection fraction; $L A$, left atrium; $V$ mean, mean transvalvular velocity; $L V V d$, left ventricular diastolic volume; $M O A$, mitral orifice area; $M R$, mitral regurgitation; $P$ mean, mean pressure gradient. All data are presented as mean \pm standard deviation.

there were no significant differences between groups for any of these outcomes. Analyses according to intention-to-treat and actual treatment received did not alter our findings.

\section{Morbidity and Mortality}

Patients were transferred from the operating room to either the postanesthetic recovery unit $(\mathrm{n}=55)$ or the intensive care unit $(\mathrm{n}=74)$, with a mean stay of $4.1 \pm 1.9$ hours and $23.0 \pm 20.7$ hours, respectively. Reoperation for bleeding occurred in 4 patients $(5.8 \%)$ in the loop group and 2 patients $(3.8 \%)$ in the leaflet resection group. Acute renal failure with indication for hemodialysis occurred in 2 patients $(2.9 \%)$ in the loop group and in none of the resection group. All perioperative complications are listed in 
TABLE 4. Early postoperative complications

\begin{tabular}{lcc}
\hline & Loops $(\mathbf{n}=\mathbf{6 9})$ & Resection $(\mathbf{n}=\mathbf{5 3})$ \\
\hline Bleeding & $4(5.8 \%)$ & $2(3.8 \%)$ \\
Low cardiac output & $2(2.9 \%)$ & $2(3.8 \%)$ \\
Hemodialysis & $2(2.9 \%)$ & 0 \\
IABP & $2(2.9 \%)$ & $1(1.8 \%)$ \\
Pacemaker & 0 & $2(3.8 \%)$ \\
Death & $2(2.9 \%)$ & 0 \\
\hline
\end{tabular}

$I A B P$, Intra-aortic balloon pump.

Table 4. There were no significant differences between the 2 groups of patients for any complication.

There were 2 perioperative (in-hospital) deaths, both occurring in the loop group. One death was due to massive pulmonary embolism, and 1 death was due to acute right heart failure. Thirty-day mortality was $1.6 \%$ for the entire patient cohort.

During follow-up, there were no episodes of thromboembolic events, myocardial infarction, stroke, endocarditis, recurrent mitral insufficiency, or valve-related reoperations in either group of patients. In addition, there were no deaths during follow-up. The mean New York Heart Association functional class was $1.2 \pm 0.4$ versus $1.1 \pm 0.36$ months postoperatively and $1.3 \pm 0.5$ versus $1.0 \pm 0.61$ year postoperatively in the loop and leaflet resection groups, respectively.

\section{Echocardiographic Follow-up}

Transthoracic echocardiography was performed 6 months and 1 year after surgery (Table 5). No significant differences were detected between the 2 groups with regard to left ventricular ejection fraction, MR grade, MV orifice area, or transvalvular velocities or gradients.

\section{DISCUSSION}

Reconstructive MV surgery aims for restoration of physiologic leaflet motion, creation of an adequately sized mitral orifice with a sufficient line of leaflet coaptation, and stabilization of the mitral annulus. ${ }^{1,11}$ Despite the fact that early

TABLE 5. Echocardiographic follow-up

\begin{tabular}{lcc}
\hline \multicolumn{1}{c}{ 6-mo follow-up } & Loops $(\mathbf{n}=\mathbf{4 2})$ & Resection $(\mathbf{n}=\mathbf{3 4})$ \\
\hline LVEF & $60.4 \pm 7.9$ & $57.3 \pm 7.9$ \\
MR grade & $0.21 \pm 0.4$ & $0.32 \pm 0.42$ \\
$P$ mean $(\mathrm{mm} \mathrm{Hg})$ & $2.36 \pm 0.97$ & $2.44 \pm 1.23$ \\
Mitral orifice area $\left(\mathrm{cm}^{2}\right)$ & $3.27 \pm 1.32$ & $2.96 \pm 1.01$ \\
& & \\
$\quad$ 1-y follow-up & Loops $(\mathbf{n}=\mathbf{3 0})$ & Resection $(\mathbf{n}=\mathbf{2 0})$ \\
\hline LVEF & $62.9 \pm 8.3$ & $59 \pm 12.3$ \\
MR grade & $0.28 \pm 0.45$ & $0.44 \pm 0.54$ \\
$P$ mean (mm Hg) & $2.34 \pm 0.96$ & $2.58 \pm 1.39$ \\
Mitral orifice area $\left(\mathrm{cm}^{2}\right)$ & $3.21 \pm 1.39$ & $3.62 \pm 1.35$ \\
\hline$L V E F$, Left ventricular ejection fraction; $M R$, mitral regurgitation. All values are \\
expressed as mean \pm standard deviation.
\end{tabular}

and long-term outcomes clearly favor MV repair over replacement, less than $60 \%$ of patients requiring MV surgery currently undergo a reparative procedure. ${ }^{13}$ The most popular technique for correction of myxomatous posterior leaflet disease is quadrangular or, more recently, triangular leaflet resection ${ }^{14,15}$ combined with a ring annuloplasty. Although these techniques have provided durable and hemodynamically satisfactory results with good long-term freedom from valve-related reoperation, partial resection of the posterior leaflet changes the anatomic and physiologic function of the MV. Reapproximation of the remnants of the posterior leaflet after resection increases its stiffness, restricts its motion, and leads to limited surface availability for coaptation with the anterior leaflet. In addition, an annular plication or sliding annuloplasty procedure is often required after leaflet resection, further increasing leaflet restriction and surgical complexity. Such annuloplasty procedures and their real or perceived complexity may be contributing to the suboptimal MV repair rate in many cardiac surgery centers. ${ }^{13}$

The concept of preserving the posterior leaflet using PTFE neochordae, rather than partial resection, has been simultaneously developed by various groups. ${ }^{3,4,16}$ The rationale of this approach follows several principles of reconstructive MV surgery: provide the largest possible orifice area, maximize the leaflet coaptation area, preserve ventriculo-annular continuity, and minimize leaflet tension. On the basis of these principles, we hypothesized that leaflet preservation with PTFE neochordae formation may optimize valvular hemodynamics and durability.

The loop technique is a modification of the use of standard PTFE sutures to create neochordae, a technique that has been successfully used for many years to correct prolapse of the anterior MV leaflet. ${ }^{17}$ The loop technique uses 4 premade PTFE (Gore-Tex) loops to facilitate chordal replacement, particularly when performed through a right lateral mini-thoracotomy. ${ }^{3,5,6,10}$ Our group recently reported excellent early and mid-term results of this technique, with a $97.4 \%$ freedom from valve related reoperation rate 3 years after single or bileaflet prolapse repair. ${ }^{5,6}$ Because reoperations for failed MV repair tend to occur in the early postoperative period, at a mean of 15 months in a large series from the Cleveland Clinic, ${ }^{18}$ we are confident that this reoperation rate should remain low over time. Although we originally developed the loop technique as a method of correcting anterior leaflet prolapse through a minimal invasive incision, we have since applied the technique to correction of posterior leaflet prolapse, as well as surgery, through a full sternotomy as we become increasingly confident with the positive results.

The current prospective randomized trial was conducted to compare the early outcome of the loop technique with the more established technique of quadrangular leaflet resection in patients with posterior MV prolapse. We chose to focus on patients with isolated posterior prolapse because this 
pathology represents the most frequently repaired form of MR. All valves could be successfully repaired in the current study, yielding an MV repair rate of $100 \%$. Echocardiographic examination revealed excellent early postoperative results with no or trace mitral insufficiency in $86.8 \%$ and mild in the remaining $13.2 \%$ of cases. We failed to find a significant difference between groups with respect to transmitral pressure gradients, MV orifice areas, or mean size of implanted MV rings. Our findings are in contrast with a small retrospective, nonrandomized study by Kudo and colleagues that demonstrated lower gradients early postoperatively in the loop group compared with leaflet resection. ${ }^{15}$ With regard to early reverse remodeling, we also failed to demonstrate a significant difference for left atrial size reduction or parameters of LV size or function between groups. Perioperative complications rates were low for both groups of patients. During follow-up, there was no valve-related reoperations and no adverse events in either group.

Before starting the study, we hypothesized that the loop technique would result in more favorable valvular hemodynamics than leaflet resection. However, we were unable to demonstrate a significant benefit of the loop technique over standard leaflet resection with regard to larger annuloplasty sizes, larger MV orifice areas, or lower transmitral gradients.

Our only statistically significant finding was that patients undergoing the loop technique had a longer line of leaflet coaptation than patients undergoing leaflet resection. It has been demonstrated that length of coaptation is an important predictor of MV repair durability in patients with ischemic MR. ${ }^{19}$ Although it may be postulated that a longer line of coaptation may also be protective in patients with myxomatous MV disease, longer follow-up will need to be performed to answer this question.

We conclude that both types of MV repair techniques can be performed with excellent early postoperative results in patients with posterior MV prolapse. The loop technique results in more leaflet coaptation but no demonstrable differences in valvular insufficiency or hemodynamics. Although longer term follow-up is required, we believe the loop technique with preservation of native tissue is a valid alternative to posterior leaflet resection. The loop technique may be particularly helpful when MV repair is performed through a minimal invasive thoracotomy.

\section{LIMITATIONS}

The number of patients included in the study may have been too small, and thus the study may have been underpowered to detect subtle differences in clinical outcomes. However, our sample size was probably sufficient to detect differences in our primary outcome-valvular hemodynamics and orifice size-because these outcomes are continuous in nature. Another study limitation is the relatively low proportion of patients who were available for echocardio- graphic follow-up 1 year postoperatively. Follow-up was limited for 2 reasons: Approximately one half of patients underwent operation within the last year of the study period, and a significant proportion of patients were referred from afar and were unwilling to return to the Heart Center Leipzig, Leipzig, Geramny, for echocardiographic follow-up. It is important to stress, however, that only $13.2 \%$ of our patients had mild MR on the predischarge echocardiogram. It is known that recurrent MR tends to recur in patients with moderate or more MR early postoperatively, ${ }^{20}$ of which none of our patients had. It is therefore unlikely that accruing a higher proportion of 1 year postoperative echocardiograms would have significantly altered our findings. The important question will be how the long-term durability of these 2 techniques compare, but longer-term follow-up will be required to address this issue.

\section{CONCLUSIONS}

This study showed that the use of PTFE neochordae (loop technique) with preservation of the posterior leaflet compares well with standard leaflet resection for the treatment of posterior MV prolapse in the early postoperative course. Both techniques resulted in good echocardiographic outcomes with low rates of morbidity and mortality. Longerterm follow-up will be required to determine whether the results continue to be comparable over time.

\section{References}

1. Carpentier A. Cardiac valve surgery-the "French correction". J Thorac Cardiovasc Surg. 1983;86:323-37.

2. David TE, Ivanov J, Armstrong S, Christie D, Rakowski H. A comparison of outcomes of mitral valve repair for degenerative disease with posterior, anterior, and bileaflet prolapse. J Thorac Cardiovasc Surg. 2005;130:1242-9.

3. Oppell UO, Mohr FW. Chordal replacement for both minimally invasive and conventional mitral valve surgery using premeasured Gore-Tex loops. Ann Thorac Surg. 2000;70:2166-8

4. Dreyfus GD, Corbi P, Rubin S, Aubert S. Posterior leaflet preservation in mitral valve prolapse: a new approach to mitral repair. J Heart Valve Dis. 2006;15: 528-30.

5. Seeburger J, Kuntze T, Mohr FW. Gore-Tex chordoplasty in degenerative mitral valve repair. Semin Thorac Cardiovasc Surg. 2007;19:111-5.

6. Kuntze T, Borger MA, Falk V, et al. Early and mid-term results of mitral valve repair using premeasured Gore-Tex loops ("loop technique"), Eur J Cardiothorac Surg. 2008;33:566-72.

7. Mohr FW, Falk V, Diegeler A, Walther T, van Son JA, Autschbach R. Minimally invasive port-access mitral valve surgery. J Thorac Cardiovasc Surg. 1998;115: 567-76.

8. Mohr FW, Onnasch JF, Falk V, et al. The evolution of minimally invasive mitral valve surgery: two years experience. Eur J Cardiothorac Surg. 1999;15:233-9.

9. Chitwood WR, Elbeery JR, Moran JM. Minimally invasive mitral valve repair: using a mini-thoracotomy and transthoracic aortic occlusion. Ann Thorac Surg. 1997;63:1477-9.

10. Seeburger J, Borger MA, Falk V, Mohr FW. Gore-Tex loop implantation for mitral valve prolapse: the Leipzig loop technique. Op Tech Thorac Cardiovasc Surg. 2008; 13:83-90.

11. Filsoufi F, Carpentier A. Reconstructive surgery in mitral valve disease. Semin Thorac Cardiovasc Surg. 2007;19:103-10.

12. Edmunds LH Jr, Clark RE, Cohn LH, Grunkemeier GL, Miller DC, Weisel RD. Guidelines for reporting morbidity and mortality after cardiac valvular operations. J Thorac Cardiovasc Surg. 1996;10:812-6.

13. Executive summary. Available at: www.sts.org/documents/pdf/ndb/Fall_2007_ Executive_Summary.pdf]. Accessed April 30, 2008. 
14. Gazoni LM, Fedoruk LM, Kern JA, et al. A simplified approach to degenerative disease: triangular resections of the mitral valve. Ann Thorac Surg. 2007;83:1658-64.

15. Sakamoto Y, Hashimoto K, Okuyama H, et al. Long-term assessment of mitral valve reconstruction with resection of the leaflets: triangular and quadrangular resection. Ann Thorac Surg. 2005;79:475-9.

16. Kudo M, Yozu R, Kokaji K, Iwanaga S. Feasibility of mitral valve repair using the loop technique. Ann Thorac Cardiovasc Surg. 2007;13:21-6.

17. David TE, Bos J, Rakowski H. Mitral valve repair by replacement of chordae tendineae with polytetrafluoroethylene sutures. J Thorac Cardiovasc Surg. 1991; 101:495-501.

18. Gillinov AM, Cosgrove DM, Lytle BW, et al. Reoperation for failure of mitral valve repair. J Thorac Cardiovasc Surg. 1997;113:467-75.

19. Kuwahara E, Otsuji Y, Iguro Y, et al. Mechanism of recurrent/persistent ischemic/ functional mitral regurgitation in the chronic phase after surgical annuloplasty: importance of augmented posterior leaflet tethering. Circulation. 2006;114(1 Suppl):I529-34.

20. Meyer MA, von Segesser LK, Hurni M, Stumpe F, Eisa K, Ruchat P. Long-term outcome after mitral valve repair: a risk factor analysis. Eur J Cardiothorac Surg. 2007;32:301-7.

\section{DISCUSSION}

Dr David Adams (New York, NY). Volkmar, I enjoyed your talk, as always. I think we all continue to learn a lot from your efforts at Leipzig in refining surgical valve strategies, particularly in the non-sternotomy setting, and this article is no exception. The fact that this was a randomized prospective MV repair trial is no small feat. Your $100 \%$ repair rate with excellent postoperative results in a consecutive series regardless of technique is a standard we should all aspire to. I think the most important aspect of this study is the emphasis on nonresective strategy, which is particularly relevant, as you showed, in the setting of fibroelastic deficiency with ruptured chordae and normal leaflet segment. I think there is a lot of misunderstanding regarding Carpentier's techniques, and I would emphasize that an overly aggressive resection is a pitfall that should be avoided. I do have some specific questions regarding your study.

First, can you clarify the extent of your quadrangular resection in the resection group? Was the entire prolapsing segment always removed or did you limit your resection to the area of prolapse between intact chords?

Dr Falk. We usually resect the complete P2 segment and do a quadrangular resection, which is completed by a sliding plasty or at least compression or plication sutures.

Dr Adams. One point I would make is oftentimes when you do that you remove nonprolapsing tissue that would be effective for your surface of coaptation. Again, a technique I learned from Dr Carpentier is that typically it is to preserve part of this P2 segment if it is nonprolapsing, and that may be one reason why you are seeing a difference.

The second question was how did you handle a deep indentation between adjacent leaflet segments associated with $\mathrm{P} 2$ prolapse in the loop group?

Dr Falk. Well, if at all, we would suture it, close it with a suture. As you noticed, there were a couple of dropouts in more complex pathologies of the posterior leaflet that were not obvious at the time of randomization, which was purely based on transthoracic echocardiography preoperatively. Some of these patients had more complex repairs, including closure of a deep indentation or placement of additional loops on the neighboring segments, usually P3 or sometimes a combination of resection and chordae replacement.
Dr Adams. Volkmar, I find the loop technique intriguing, and I just have 1 question about it. It is obviously effective. When you attach multiple chords with the loop technique along the edge of a leaflet from a single attachment in the ventricle, the respective lengths should change as you move away from the point of papillary muscle attachment. What is the limit of prolapse you can correct with a single-loop apparatus?

Dr Falk. In case of a large prolapse involving 1 or more segments the loops may not arise from 1 papillary muscle alone, for the reason you just pointed out. We would therefore use multiple loops from both papillary muscles, always trying to avoid to cross the midline.

Dr Adams. My next question is regarding the measuring of the coaptation depth. The main difference between the 2 techniques, although significant, was only $1.7 \mathrm{~mm}$, and in my experience I have not found transesophageal echocardiography to be sensitive to the millimeter level for that measurement. Can you please clarify if the grading was done in a blinded fashion and did 1 reader make all of the measurements?

Dr Falk. Coaptation length was measured in the operating room and reviewed by 2 different echocardiographers. Without argue, the difference may look small but may have an important effect for long-term durability. I could show you a number of examples with excellent coaptation using the loop technique as opposed to a number of patients in whom we found little apposition with the resection technique. A retrospective analysis of our overall series of more than 1600 minimally invasive MV repairs showed that preserving the posterior leaflet yields a better long-term freedom from valve-related reoperation. However, this randomized trial was not powered to demonstrate any difference in clinical outcomes.

Dr Adams. I would just again caution that that probably relates to the amount of leaflet, normal leaflet tissue, you resect when you have a P2 prolapse. But I think the message of your work, which is so important and which we continue to learn, is that we have to respect tissue, and whether you choose a limited resection, quadrangular resection, or nonresection technique, including PTFE (Gore-Tex), chordal plasty, or chordal transfer, all of that is going to be important to optimize the surface of coaptation.

I think it is interesting. Your group is doing what others are doing. We have stopped talking about MR. We are fixing that. I think we have learned from Tirone's data that because of the recurrence of MR, the focus is shifting from not which repair technique we use but the surface of coaptation, not about how we solve MR but how good is the repair in terms of durability. I think this article is really important for that.

Dr Craig Miller (Stanford, Calif). Could you tell what fraction of your patients had real myxomatous disease, Barlow's, and what fraction had the older fibroelastic deficiency?

Dr Falk. You saw the long time span for including patients in this study. We only included patients with pure $\mathrm{P} 2$ prolapse caused by fibroelastic deficiency. There was, by intention, no Barlow's in this group. This is a different group of patients requiring more extensive surgery involving the anterior leaflet and therefore is not useful for a comparison.

Dr Michael Hasenkam (Aarhus, Denmark). You correctly alluded to the importance of having low stress on the subvalvular apparatus and, in particular, the leading edge chordae. But could you in your studies postoperatively assess in some indirect way the tension that you have on the loops that you implant? 
Dr Falk. I am not aware of any measurement to address tension on the loops. Therefore, I don't have an answer to that question.

Dr Hasenkam. Because if you could indirectly assess that by visualization of the movements of the leaflet, it could be a important postoperative assessment for long-term application.

Dr Falk. I agree. We saw preserved mobility of the leaflet with neochordae replacement as opposed to the resection technique. At this meeting, an experiment in an in vitro left heart simulator study on MV hemodynamics after MV repair using either a quadrangular or triangular resection versus neochordoplasty was presented by Padala and Adams. This elegant study supports our findings because the authors demonstrated improved coaptation and preserved mobility of the posterior leaflets with neochordae.

Dr Prasad Krishnan (Bangalore, India). Systolic anterior motion (SAM) of the MV is a phenomenon that is seen after resection of the posterior mitral leaflet, but because we started implanting artificial chordae to repair the valve, we have seldom seen SAM in the intraoperative echocardiograms after repair. Is this a phenomenon that you have observed or have you looked into this aspect?

Dr Falk. In this particular group we had no SAM, but it has occurred in our practice. SAM is usually caused by using too long loops that create a bulging excess $\mathrm{P} 2$ segment that pushes the anterior leaflet toward the left ventricular outflow tract. It is therefore important to exactly size the neochordae to create enough pull so that SAM cannot occur.

Dr Vaughn Starnes (Los Angeles, Calif). I congratulate Dr Falk on a nice study. This is related to Dr Krishnan's question also. When we see a large prolapsing P2 segment, we often see a roughened surface and a smooth surface representing a true leaflet portion. Where do you place the chords to avoid SAM, and are there some preoperative predictors on the echocardiogram that would favor resection over chordal insertion, such as a long anterior leaflet where you think the coaptation line is going to be high up in the ventricle and cause SAM?

Dr Falk. As you know, there are a number of parameters that you can derive from echocardiography that are predictive for the occurrence of SAM after MV repair, including an anterior mitral leaflet to posterior mitral leaflet ratio of less than 1.4 , a posterior mitral leaflet height of more than $1.5 \mathrm{~cm}$, and a C-sept distance of less than $2.6 \mathrm{~cm}$. If you plan to preserve the posterior leaflet, it is important to use short chords, and in terms of insertion, to use the body of the leaflet to avoid SAM. The idea is not to have full mobility of this leaflet but rather to pull it down and have it serve as a large coaptation area or landing zone for the anterior leaflet. So functionally the mobility is impaired, but by doing so, there is little risk of SAM. In certain constellations prone for SAM, it may be advisable to consider a resection technique.

Dr Craig Miller (Stanford, Calif). But SAM is not going to be a real issue in elderly patients with fibroelastic deficiency.

Dr Falk. Sorry?

Dr Miller. SAM will not be a big issue in the examples you have shown us. These are older people with fibroelastic deficiency, and those posterior leaflets are not all that tall.
Dr Falk. I agree, these were selected patients not prone for SAM.

Dr Miller. I think Vaughn was asking where you do insert the neochords on the P2 scallop, how far back from the free margin? The junction of smooth zone, rough zone?

Dr Falk. That would depend on the excess tissue that is present. The more excess tissue, the more into the body we would insert the loops while still using relatively short chords.

Dr Robert Dion (Genk, Belgium). Volkmar, congratulations. This was very neatly presented. Don't you think you should maybe adapt your conclusion and not oppose one technique to the other one, because it depends very much on the quality of the P2 prolapsing tissue. If it is a huge, yellowish, thick tissue, I think you should favor resection, and if it is a more normal-looking valve segment, I think you should use neochordae. In my practice, I use both techniques, partial resection and a chord.

It is a beautiful study because it is prospective and randomized, but I am not sure that you can conclude that one technique is better than the other one. By the way, a 6-mm coaptation is, in nature, normal. I think you have proven that you can achieve perfect results with a multiloop technique, but don't you think you should be less exclusive and conclude that the chosen technique should depend on the quality of the prolapsing tissue?

Dr Falk. As you noticed, I was cautious with my conclusion. I didn't really say one technique was better than the other. My sole conclusion from the presented data is that we can expect a larger coaptation area with the loop technique. You rightfully point out that there are patients with too much excess tissue that requires a resection, and you may have noticed that this was the reason for some dropouts and crossovers in this study. There are circumstances when you would prefer one technique over the other. I guess the bottom line is that one should have as many repair techniques as possible in one's armamentarium and use them appropriately.

Dr Harold Roberts (Lauderdale Lakes, Fla). I enjoyed the presentation. I actually made a trip to Germany a few years ago just to try to incorporate this technique into my practice; however, a major limitation for us is that it is difficult to have these loops prepackaged and ready to go in various sizes, and unfortunately we don't have access to Frau Conradt in Fort Lauderdale. Has there been any interest from the industry in prepackaging these loops? I think you would achieve a wider use of this technique if such was available in the United States.

Dr Falk. So far no company has decided to manufacture these loops. For the time being they are custom-made on site. It is unfortunate, but none of the companies around have decided to pick up the technology and do it.

Dr Miller. Or you can do it yourself.

Dr Falk. Or you can do it yourself, right.

Dr Miller. Volkmar, fine presentation, excellent study. We congratulate you and your colleagues for going the extra kilometer to do this right (randomized, prospective), and we look forward to the longer-term results. 